\title{
Topical Phenylephrine Solution
}

National Cancer Institute

\section{Source}

National Cancer Institute. Topical Phenylephrine Solution. NCI Thesaurus. Code C91075.

A topical solution containing phenylephrine, a sympathomimetic amine with

vasoconstricting activity. Upon topical application to the oral mucosa, phenylephrine may activate alpha-adrenergic receptors in the mucosa thereby causing vasoconstriction. As a result, this agent may reduce swelling of the mucosal membranes and decrease radiotherapy-induced mucositis. 